\title{
THE NORMAL BALLISTOCARDIOGRAM
}

\author{
BY \\ LEON BROTMACHER \\ From the Cardiac Department, Cardiff Royal Infirmary
}

Received March 16, 1955

The use of ballistocardiography in clinical practice has been greatly simplified by the introduction by Dock and Taubman (1949) of the direct pick-up which can be used in home or hospital. Each type of instrument has its own physical characteristics, and criteria for normality have to be defined for each. Brown et al. (1952) working with the high-frequency table ballistocardiograph emphasized that the systolic waves must be constant in form and uniform in duration, and classified degrees of abnormality as follows.

Grade 1. Complexes normal in form; the expiratory amplitude less than half that of inspiration.

Grade 2. Decrease in inspiratory amplitude; half or more of the complexes abnormal.

Grade 3. Complexes identifiable but variable; abnormalities present throughout.

Grade 4. Complexes small, irregular, and unidentifiable.

Dock et al. (1953), who use a direct body pick-up, allow a minority of abnormal complexes in Grade 1, and group with Grade 2 those tracings with marked respiratory variation in which the smaller complexes outnumber the larger. An abnormal pattern is defined as one in which the depth of the first downstroke is less than one-tenth of the height of the main systolic upstroke, the amplitudes of the $\mathrm{H}$ and $\mathrm{K}$ waves are respectively over 50 and 80 per cent of that of the $J$ wave, or the upward diastolic deflections are larger than the systolic ones. Scarborough et al. (1953), with a highfrequency table, found no definitely abnormal ballistocardiograms in 137 healthy persons aged twenty to forty. Using a photo-electric apparatus, Pordy et al. (1951) found only 3 abnormal in 44 normal subjects under fifty. The incidence of abnormality increased with age in both groups.

Abnormalities in the ballistocardiogram have been made the basis of far-reaching conclusions. Henderson (1953) considered changes in wave form after smoking evidence of the deleterious effect of tobacco on the myocardium. Brown et al. (1950) regarded a normal tracing as strong evidence against the presence of angina pectoris. Starr (1947) concluded from an 8-10 year follow up of 90 healthy subjects that abnormalities in the older age group are associated with a high incidence of cardiovascular disease and considered (1952) finding an abnormal tracing in an apparently healthy subject sufficient to warrant modification of the person's way of life.

The present study was undertaken in order to re-assess the criteria for normality in the light of these claims.

\section{Methods AND MATERials}

Ballistocardiograms of 200 subjects between 14 and 65 years of age were recorded, using a Sanborn photo-electric direct body pick-up and a Sanborn Polyviso 4-channel recorder. The first hundred were drawn from students, doctors, and technical staff, and the remainder from patients without cardiac disease or any condition, such as thyrotoxicosis, known to affect the ballistocardiogram. Some diabetics and a few very mild asthmatics in a quiescent phase were included. No abnormality was found in any subject on clinical, electrocardiographic, or radiological examination. No patient had a blood pressure of over $170 / 100 \mathrm{~mm}$.

The ballistocardiogram was recorded at least two hours after a meal. Smoking was forbidden for the previous hour and any exertion for the previous fifteen minutes. No patients were taking any drugs with an action on the heart. 
When the effects of respiratory distortion are eliminated by use of a filter, some means of distinguishing between complexes produced during inspiration and expiration become necessary. Initially, simultaneous pneumograms were recorded, using a rubber catheter inserted into one nostril and connected to a Sanborn electromanometer. It was later found that with the subject breathing quietly through his mouth and his head resting on a large, soft pillow, respiratory movement was detectable, but distortion minimal even without the filter, so that the pneumogram became unnecessary. Even when the unfiltered records were not wholly satisfactory, they could be used to identify the inspiratory and expiratory complexes in the filtered record.

In 79 subjects, the sensitivity of the recorder was standardized so that $1 \mathrm{mv}$. produced a $1 \mathrm{~cm}$. deflection; in the remainder it was adjusted so as to give the most satisfactory wave form. Tracings were taken with the subject lying either on the floor or on a built-in laboratory bench. Vibration of the building did not constitute a problem.

Insufficient emphasis has been laid on the practical difficulties inherent in ballistocardiography. A degree of patient co-operation comparable to that required for an estimation of the basal metabolic rate is needed. An unsatisfactory tracing may result from lack of co-operation, inability to lie flat or to relax, involuntary leg movements, and local conditions making resting of the crossbar squarely across the shins impossible. Of 100 patients, selected at random, to be assessed for suitability for ballistocardiographic examination, 16 were found to be temporarily and 25 permanently unsuitable, the reasons ranging from severe orthopnœa to a leg amputation.

The grosser departures from normal are associated with an irregular, non-repetitive trace without clearly identifiable complexes, so that a Grade 3 or 4 ballistocardiogram gives a superficial impression of being a technically poor tracing. However, observations on the effect on the normal ballistocardiogram of deliberately produced muscle tension, foot movement, and involuntary tremor resulting from fatigue showed that it was not possible to reproduce any of the pathological forms. The complexes, though often impossible to interpret owing to distortion, remained clearly distinguishable and there were marked deviations in the base line, which remained level in an abnormal but technically satisfactory tracing.

A number of tracings had to be rejected in the light of these findings as technically too poor to be interpreted, the figure of $\mathbf{2 0 0}$ for the series being reached after this elimination. Faulty recording was almost always associated with visible body and leg movement or obvious irregularities in the movement of the light beam, as seen in the window of the photo-electric cell.

\section{RESULTS}

Applying Dock's criteria, 128 were found to be normal (Fig. 1), 23 to show a Grade 1, 2 a Grade 2, 4 a Grade 3, and 1 a Grade 4 abnormality: the remaining 44 did not fit into any of these groups. Category 1 in Tables I and II included 32 who were normal apart from an excessively large $\mathrm{K}$ wave, whose size in relation to the $\mathrm{J}$ wave varied between $0.8: 1$ and $1.5: 1$. It was often the dominant downward stroke and occasionally the most prominent stroke of the whole complex (Fig. 2): it varied in shape, being pointed, rounded, notched, or asymmetrical on account of a gently sloping upstroke.

In 4 ballistocardiograms, the I wave failed to reach the base line, 2 showed large $\mathrm{H}$ waves, and 2 upward diastolic deflections that were larger than the systolic. This group of 8 , classed in

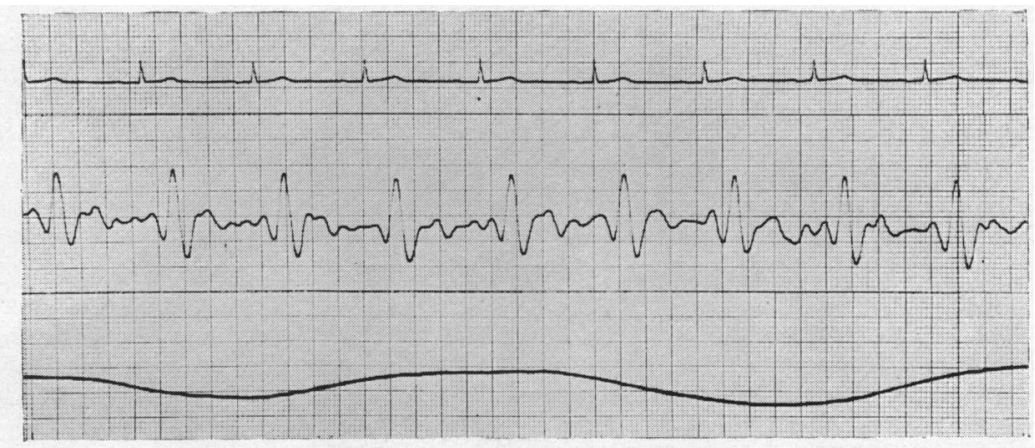

Fig. 1.-Normal ballistocardiogram obtained from a 26-year-old man. The pneumogram moves downwards during inspiration. 


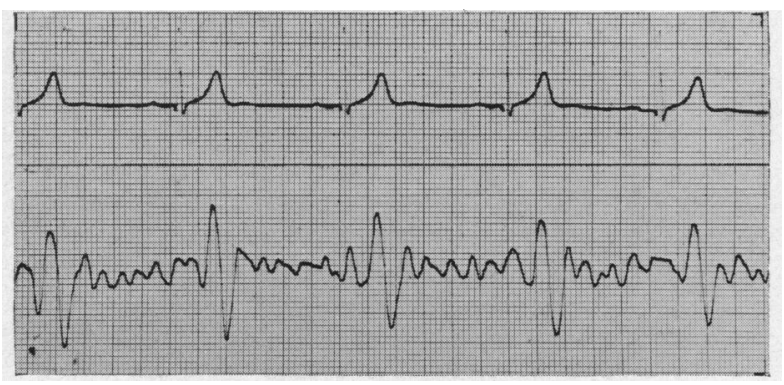

FIG. 2.-Tracing showing very deep $\mathrm{K}$ waves. From a 23-year-old male student.

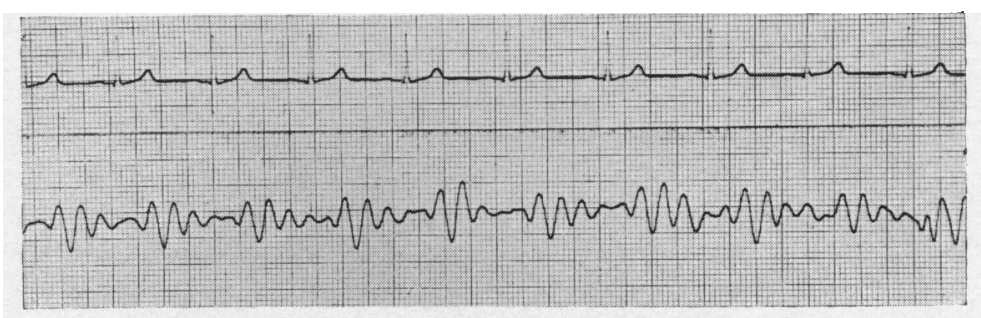

FIG. 3.-Ballistocardiogram of a 22-year-old woman student. In several complexes the diastolic waves are larger than the systolic ones.

Tables I and II as Category 2, has been divided into sub-groups (a) and (b), containing respectively a minority and a majority of abnormal waves. The former group included three with subnormal I waves, one with large $\mathrm{H}$ waves, and one with large diastolic waves (Fig. 3).

The subjects in Grade 1 and the two special categories did not include an unduly high percentage of patients with conditions such as diabetes, likely to be associated with cardiac disease. The proportion indulging in strenuous exercise was only slightly less than among the normals. The group with deep $\mathrm{K}$ waves, the form usually associated with hypertension, contained only one person with a blood pressure of over 160/90. None of these departures from normal was associated with marked axis deviation. There was a tendency for Grade 1 to include a relatively larger number of underweight patients, but about a quarter of this group was actually overweight.

The students and staff were all under 35 years of age. The patients in this age group are distributed among the various classes in a manner similar to that of students and staff (Table I). The

TABLE I

Incidence of Abnormal Ballistocardiograms among Healthy Subjects and Patients with Non-Cardiac CONDITIONS UNDER 35 YEARS

\begin{tabular}{|c|c|c|c|c|c|c|c|c|}
\hline & & & & & \multicolumn{2}{|c|}{ Students and staff } & \multicolumn{2}{|c|}{ Patients } \\
\hline & & & & & No. & Percentage & No. & Percentage \\
\hline $\begin{array}{l}\text { Normal ... } \\
\text { Grade } 1 \\
\text { Grade } 2 \\
\text { Grade } 3 \\
\text { Grade } 4 \\
\text { Category 1 } \\
\text { Category 2(a) } \\
\text { Cateogry 2(b) }\end{array}$ & $\begin{array}{l}. . \\
\cdots \\
\cdots \\
\cdots \\
\cdots \\
\cdots\end{array}$ & $\begin{array}{l}. \\
\cdots \\
\cdots \\
\cdots \\
\cdots \\
\cdots \\
\cdots\end{array}$ & $\begin{array}{l}. \\
\cdots \\
\cdots \\
. \\
\cdots \\
\cdots \\
\cdots\end{array}$ & $\begin{array}{l}. . \\
\cdots \\
\ldots \\
\cdots \\
\cdots \\
\cdots \\
\cdots\end{array}$ & $\begin{array}{r}73 \\
4 \\
0 \\
0 \\
0 \\
21 \\
2 \\
0 \\
\end{array}$ & $\begin{array}{r}73 \\
4 \\
0 \\
0 \\
0 \\
21 \\
2 \\
0\end{array}$ & $\begin{array}{r}26 \\
6 \\
0 \\
1 \\
0 \\
5 \\
3 \\
2 \\
\end{array}$ & $\begin{array}{r}62 \\
14 \\
0 \\
2 \\
0 \\
11 \\
7 \\
4\end{array}$ \\
\hline & & & & & 100 & & 43 & \\
\hline
\end{tabular}


TABLE II

Classification of Cases on Basis of Age and Sex

\begin{tabular}{|c|c|c|c|c|c|c|c|c|c|c|c|}
\hline & & & \multicolumn{3}{|c|}{ Under 45} & \multicolumn{3}{|c|}{ Over 45} & \multicolumn{3}{|c|}{ All ages } \\
\hline & & & Men & Women & Both sexes & Men & Women & Both sexes & Men & Women & Both sexes \\
\hline \multirow{2}{*}{\multicolumn{2}{|c|}{$\begin{array}{ll}\text { Normal } & \ldots \\
\text { Grade } 1 & \ldots \\
\text { Grade 2 } & \ldots \\
\text { Grade 3 } & \ldots \\
\text { Grade 4 } & \ldots \\
\text { Category } & 1 \ldots \\
\text { Category } & 2(a) \\
\text { Category } & \text { 2(b) }\end{array}$}} & $\begin{array}{l}\ldots \\
\ldots \\
\ldots \\
\ldots \\
\ldots \\
\ldots \\
\ldots\end{array}$ & $\begin{array}{r}73 \\
15 \\
0 \\
2 \\
0 \\
21 \\
4 \\
2\end{array}$ & $\begin{array}{r}46 \\
1 \\
0 \\
0 \\
0 \\
8 \\
2 \\
1\end{array}$ & $\begin{array}{r}119 \\
16 \\
0 \\
2 \\
0 \\
29 \\
6 \\
3\end{array}$ & $\begin{array}{l}5 \\
7 \\
2 \\
1 \\
1 \\
3 \\
0 \\
0\end{array}$ & $\begin{array}{l}4 \\
0 \\
1 \\
1 \\
0 \\
0 \\
0 \\
0\end{array}$ & $\begin{array}{l}9 \\
7 \\
3 \\
2 \\
1 \\
3 \\
0 \\
0\end{array}$ & $\begin{array}{r}78 \\
22 \\
2 \\
3 \\
1 \\
24 \\
4 \\
2\end{array}$ & $\begin{array}{r}50 \\
1 \\
1 \\
1 \\
0 \\
8 \\
2 \\
1\end{array}$ & $\begin{array}{r}128 \\
23 \\
3 \\
4 \\
1 \\
32 \\
6 \\
3\end{array}$ \\
\hline & & & 117 & 58 & 175 & $\overline{19}$ & $\overline{6}$ & $\overline{25}$ & 136 & $\overline{64}$ & 200 \\
\hline
\end{tabular}

incidence of abnormality among the patients over 45 was appreciably greater than that among patients below this age. There are rather fewer men normals than women owing to a larger number of the former in Grade 1; but the sex difference is not associated with differences in age distribution (Table II).

The constancy of the HK interval was confirmed in the case of the normal ballistocardiograms. In six Grade 1 tracings there was a variation, not constantly related to respiration, of up to $0.04 \mathrm{sec}$. and in one case in each special category there were differences of up to $0.08 \mathrm{sec}$. With greater degrees of abnormality, measurement of the HK interval became increasingly difficult, owing to irregularity of the waves. The complexes were clearly defined and identifiable in all but the Grade 4 cases and some of the expiratory waves in three Grade 3 cases. No obvious variation in the relative timing of the ballistocardiogram and electrocardiogram was seen.

The complexes, even in the normals, vary with respiration and from cycle to cycle as the cardiac and respiratory rates are unrelated, and, consequently, in each cycle systolic complexes occur in slightly different positions relative to the peaks of inspiration and expiration. This tendency is naturally greatest in the Grade 1 tracings in which the respiratory variation is great and complexes may be increasing threefold in size in the course of three or four beats. Since the shorter expiratory complexes have the same width as the inspiratory, their shapes are necessarily somewhat different and the peaks of the waves more rounded (Fig. 4). The records in the two special categories were no more variable than the normals. Single complexes that differed markedly from all others were seen not infrequently and considered to be artefacts.

With one exception, when the recorder sensitivity was standardized, the $I J$ waves of the normals fell in the ranges 5-22 $\mathrm{mm}$. and 4-15 mm. in inspiration and expiration respectively. The IJ wave amplitudes of the subjects in Grade 1 and the two special categories lay within these limits. Among the normals in this group, who were all aged forty and under, there was a positive correlation

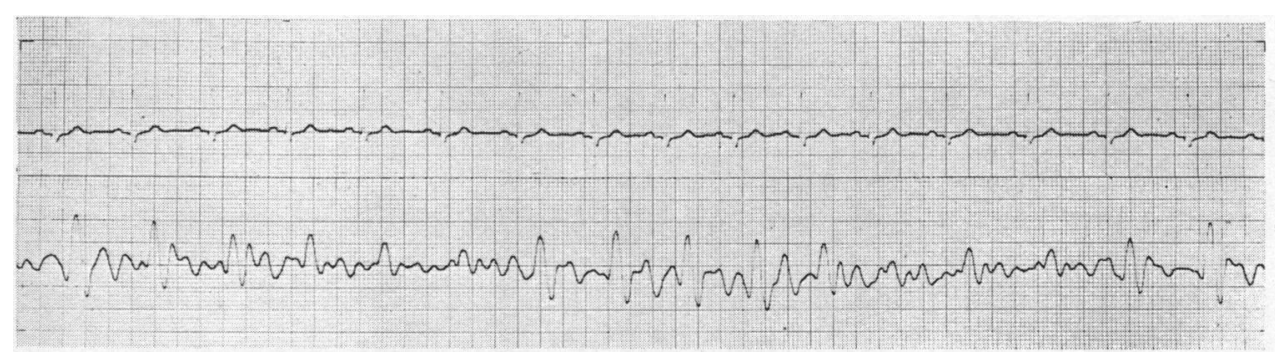

FIG. 4.-Grade 1 ballistocardiogram obtained from a 42-year-old patient admitted for treatment of a fistula-in-ano. 
between mean IJ wave amplitude and height of subject $(\mathrm{r}=0.37, \mathrm{~N}=59 ; \mathrm{P}<0.01)$, but not with weight $(r=0.05)$.

The observations were repeated on 20 members of the student-staff group at intervals ranging from one month to two years. The pattern was virtually identical in 13, and in a further 5 the systolic complexes were similar, though there were differences in the diastolic ones (Fig. 5), a variable number of $\mathrm{L}$ waves being larger than the $\mathrm{J}$ waves: these have been classified on the basis of the earlier findings. The remaining 2 showed changes in the relative depths of the $\mathrm{I}$ and $\mathrm{K}$ waves, but were normal on both occasions.

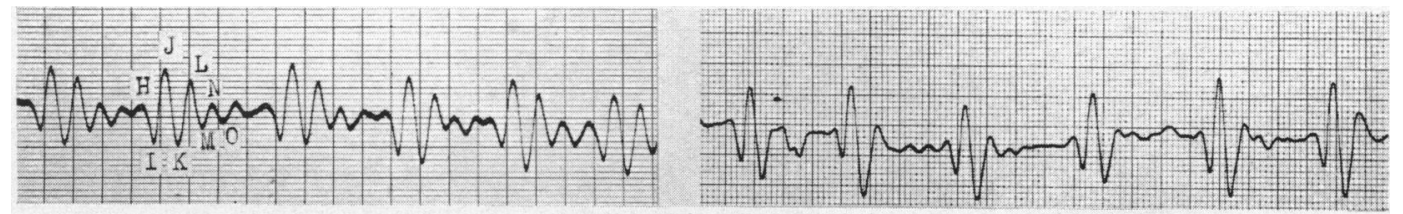

Fig. 5.-Tracings obtained from a healthy 24-year-old woman before and after an interval of twenty-two months. The right-hand tracing, which is the later one, shows some decrease in the size of the diastolic complexes, but no change in the systolic ones.

\section{Discussion}

The decision to regard any observation as abnormal is necessarily based on studies of a group of apparently healthy people. The range accepted as physiological is usually one within which the vast majority, rather than the complete population, fall. A conclusion that a particular finding is pathological must always be made with this reservation.

On this basis, ballistocardiograms with continuous abnormalities, such as very large $\mathrm{H}$ waves or diastolic deflections, could be regarded as abnormal, being present in only 1.5 per cent of a large series of normal subjects. Similarly, Grades 2,3 , and 4 , with a combined incidence of 4 per cent, could be considered pathological. It can be seen from Table II that all these types of pathological tracings were seen in only 3 per cent of subjects under 45 years of age.

Similar considerations apply to systolic waves with the form of the letter $M$. The " early $M$ " associated with an abnormally large $\mathbf{H}$ wave, was seen only four times, and then not in a fully developed form. The " late $M$ " produced by a reduplication of the I wave, was not seen at all. The $J$ wave was occasionally slurred, but never notched or split. The complexes were clear cut in all but the Grade 4 and three of the Grade 3 tracings, and absence of definition is, in consequence, to be regarded as abnormal.

On the other hand, the incidence of Grade I tracings is such that they can be regarded as a normal finding, especially in view of their occurrence in the early age groups. The factors that are thought to produce the respiratory changes in the ballistocardiogram, i.e. the effect of respiration on the blood flow in the venæ cavæ and pulmonary veins, and secondarily on the output and force of contraction of the right and left ventricles, is enormously variable. The respiratory alteration in ballistocardiographic amplitude shows a continuous gradation from an amount that is hardly detectable to a more than threefold inspiratory increase, and any distinction drawn between tracings in which the change is more than twofold and those in which it is less is purely arbitrary. Jones (1952), using the low-frequency table ballistocardiograph, found this feature equally commonly in groups of patients with and without arteriosclerotic heart disease.

It seems logical, furthermore, to consider as normal the ballistocardiograms of Category 2 (a), i.e. those without marked respiratory change but with a minority of abnormal complexes, since some Grade 1 tracings show the latter feature (Fig. 4). Abrams and Edger (1953), using an electromagnetic instrument, noted the presence of I wave abnormalities in the course of a survey of 319 healthy soldiers: there were unusually large $\mathrm{H}$ and $\mathrm{L}$ waves in 1 per cent and 6 per cent respectively, the latter being considered normal by them.

Similar reasoning suggests that ballistocardiograms with deep $\mathrm{K}$ waves should be considered physiological. There is a continuous gradation from very shallow to very deep $K$ waves, and their amplitude is often lessened by use of the filter. Their measurement depends on the rather arbitrary drawing of a base line which can often be placed at varying levels. Mandelbaum and Mandelbaum (1951) suggest that this type of complex can occur in tall, thin subjects, though it was by no means confined to this type in the 
present series. In any case, this feature can hardly supplant the sphygmomanometer as a means of detecting hypertension, and the observation of Brown et al. (1952) that the $\mathrm{K}$ wave becomes much shallower when the blood pressure is reduced by Veratrum viride means that this type of complex is of no value in the detection of previous hypertension, in, say, a patient suffering from shock.

Table III shows the incidence of normality in the series when the revised criteria now being suggested are accepted. The age trend is still apparent, but the sex difference largely disappears.

TABLE III

Percentage of Normals using Revised Criteria

\begin{tabular}{|c|c|c|c|c|c|c|}
\hline & & Over 45 & Under 45 & Men & Women & Total \\
\hline $\begin{array}{l}\text { Normal } \\
\text { Abnormal }\end{array}$ & $\begin{array}{ll}. & . \\
. . & .\end{array}$ & $\begin{array}{l}\text { No. } \\
19(76 \%) \\
6(24 \%) \\
\frac{25}{25}\end{array}$ & $\begin{array}{l}\text { No. } \\
170(97 \%) \\
5(3 \%) \\
\frac{175}{(3 \%)}\end{array}$ & $\begin{array}{l}\text { No. } \\
128(94 \cdot 5 \%) \\
8(6 \%) \\
\frac{136}{(6 \%)}\end{array}$ & $\begin{array}{l}\text { No. } \\
61(94 \%) \\
\frac{3}{64}(5 \cdot 5 \%)\end{array}$ & $\begin{array}{l}\text { No. } \\
189(94.5 \%) \\
11(5 \cdot 5 \%) \\
\frac{200}{}\end{array}$ \\
\hline
\end{tabular}

By standardizing the recording apparatus, it is possible to compare tracings with each other, and, on an empirical basis, to define for each height and age group, a range for the $I J$ amplitude beyond which a normal is unlikely to fall (Fig. 6). The photo-electric instrument cannot, however, be used quantitatively, e.g. to measure cardiac output, as the responses of the body to a vibrating and a momentary force are totally different, and a valid method of calibration, which must be based on the response of the body to the former, has not as yet been devised.

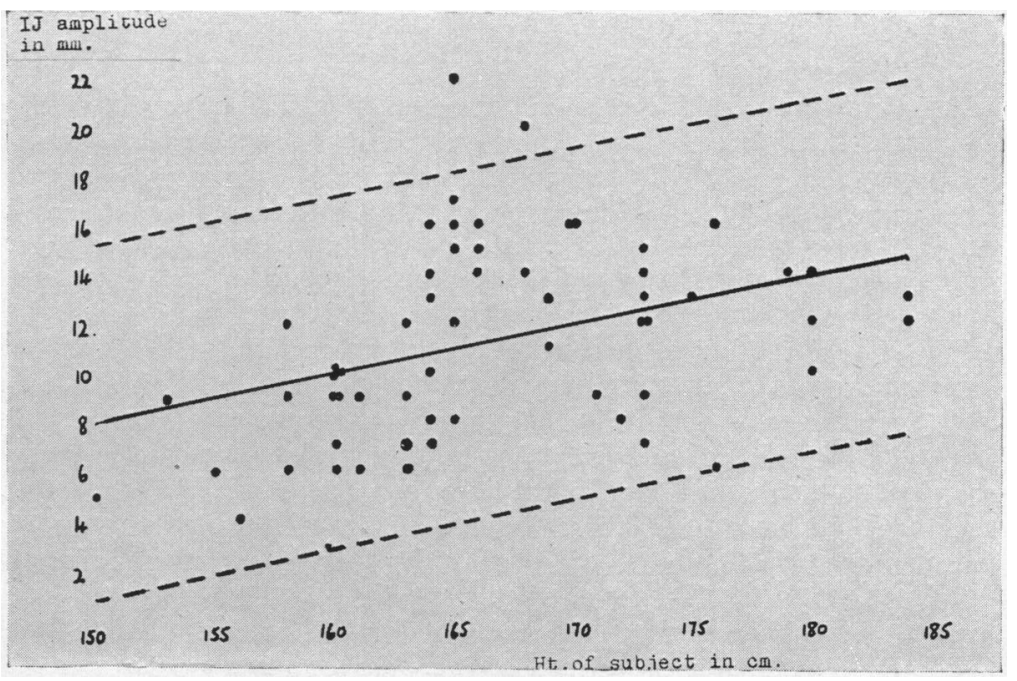

FIG. 6.-Relation of IJ amplitude to height of subject. The continuous and interrupted lines indicate the regression line and the 95 per cent confidence limits respectively.

The results were found to be constant during any one period of observation suggesting that short-term variations, such as those described by Henderson (1953), reflect real cardiovascular changes.

These conclusions suggest that ballistocardiography is of more limited use than has hitherto been suggested. Its value in large-scale surveys is limited by the need to select from the population to be studied those with the ability and willingness to co-operate. Comparing different series, as in an endeavour to assess the incidence of cardiac involvement in a particular disease, would only be possible when the distribution of abnormalities is likely to be the same among the sections of the population that can and cannot be tested. This assumption could not be made in the case of diabetes, for example. Here, the type of person 
able to co-operate adequately in the test is likely to be the type of person who would approach his illness more sensibly and be better controlled, with resulting freedom from complications.

The ballistocardiograph detects weakening of the contractile force of the myocardium but not its cause. The typical patterns that have been described in a number of conditions, such as coarctation of the aorta and mitral stenosis, are of theoretical interest, but do not assist in diagnosis or assessment.

Ballistocardiography will stand or fall as an instrument of clinical practice by its value in the diagnosis and assessment of ischæmic heart disease. Previous concepts concerning its value in the subject with possible angina need modification. The series of Brown et al. (1950) included 5 typical and 10 atypical cases in which the diagnosis of ischæmic heart disease was maintained in the absence of evidence of cardiac abnormality: they claimed that all of these had abnormal ballistocardiograms, though in 3 of each group there were Grade 1 records. Starr (1952), who does not attach much importance to marked respiratory variation, and Scarborough et al. (1953), who have demonstrated it in normal subjects in the older age groups, have reported physiological tracings in patients with angina (Starr and Wood, 1943; Scarborough et al. 1952). The differences, however, may not be wholly attributable to differing interpretations of the significance of respiratory variation.

The single Grade 4 tracing in the present series was obtained from a subject with a considerably unfolded aorta. Dock (1954) has shown that this is often associated with pathological longitudinal but normal lateral ballistocardiograms and has suggested that change in direction of forces generated by a normal contraction of the heart is responsible. It would seem, therefore, that in a person with this feature no significance can be attached to a record that is grossly pathological. The need for a lateral tracing in these cases detracts considerably from the principal advantage of the photo-electric instrument-its simplicity.

The evidence presented suggests that a normal ballistocardiogram showing no marked respiratory variation is, in older subjects, evidence against the presence of ischæmic heart disease, and that a grossly abnormal finding in a young person with no unfolding of the aorta is to be considered pathological. The conclusions apply equally to the diagnosis of angina pectoris or coronary thrombosis, past or present. Observations need to be made on subjects with suspected ischæmic heart disease in conjunction with an assessment of the position of the heart and the state of the aorta, and the ballistocardiograms with marked respiratory variation classified separately. Long-term studies are needed in order to determine whether there is a difference in prognosis in clinically comparable cases of proven coronary artery disease with normal and abnormal ballistocardiograms.

\section{SUMmARY AND CONCLUSIONS}

Ballistocardiographic observations were made on 200 subjects without evidence of cardiovascular disease, using a photo-electric apparatus. The technical difficulties and the fallacies of quantitative deductions were pointed out. Qualitative analysis showed that 64 per cent were normal according to criteria laid down for the instrument. It was suggested that tracings in which there were a minority of abnormal complexes, with or without marked respiratory variation, and tracings normal apart from a large final systolic downstroke should be regarded as physiological. On this basis, 94.5 per cent of the tracings were normal. With the new criteria, as with the old, there was an increasing incidence of abnormality with increasing age.

The following conclusions about the practical values of ballistocardiography were reached.

(1) It can be used to assess the incidence of cardiac involvement in generalized disease processes, though problems of bias in selection arise.

(2) The effect of any agent, e.g. tobacco, on the cardiovascular system can be detected by observation of short-term changes.

(3) In a young subject with a vertical heart and no aortic unfolding, a grossly abnormal ballistocardiogram is evidence in favour of cardiac disease, and a normal tracing without respiratory variation suggests the presence of a normal heart, especially in an older person.

Dr. William Phillips suggested this work and has given continued advice and encouragement; Dr. Lewis Fanning provided statistical help; Dr. Gerald D. Davies recorded a large number of the ballistocardiograms; Miss C. Rumbelow and Miss D. Francis gave valuable technical assistance; to these and to the consultant staff of Cardiff Royal Infirmary who permitted me to study their patients I am much indebted. 


\section{REFERENCES}

Abrams, W. B., and Edger, H. D. (1953). Circulation, 8, 738.

Brown, H. R. Jr., Hoffman, M. J., and de Lalla, V. (1950). Circulation, 1, 132.

_, de Lalla, V., Epstein, M. A., and Hoffman, M. J. (1952). Clinical Ballistocardiography. The MacMillan Co., New York.

Dock, W. (1954). Amer. J. med. Sci., 228, 125.

-, Mandelbaum, H., and Mandelbaum, R. A. (1953). Ballistocardiography. The C. V. Mosby Co., St. Louis. and Taubman, F. (1949). Amer. J. Med., 7, 751.

Henderson, C. B. (1953). Brit. Heart J., 15, 278.

Jones, R. J. (1952). Circulation, 6, 389.

Mandelbaum, H., and Mandelbaum, R. A. (1951). Circulation, 3, 663.

Pordy, L., Taymor, R. C., Moser, M., Chesky, K., and Master, A. M. (1951). Amer. Heart J., 42, 321.

Scarborough, W. R., Mason, R. E., Davis, F. W., Jr., Singewald, M. L., and Baker, B. M. Jr. (1952). Amer. Heart J., 44, 645.

Davis, F. W. Jr., Baker, B. M. Jr., Mason, R. E. Jr., Singewald, M. L., Lore, S. A., and Fox, L. M. (1953). Amer. Heart J., 45, 161.

Starr, I. (1947). Amer. J. med. Sci., 214, 233. , (1952). Ann. intern. Med., 37, 839.

_, and Wood, F. C. (1943). Amer. Heart J., 25, 81. 